\title{
The Concept of Happiness as Conveyed in Visual Representations: Analysis of the Work of Early Childhood Educators
}

\author{
Gila Russo-Zimet ${ }^{1}, \&$ Sarit Segel ${ }^{1}$ \\ ${ }^{1}$ Levinsky College of Education, Israel \\ Correspondence: Gila Russo-Zimet, Levinsky College of Education, Israel
}

Received: June 9, 2014 Accepted: June 24, 2014 Online Published: September 5, 2014

doi:10.11114/jets.v2i4.436

URL: http://dx.doi.org/10.11114/jets.v2i4.436

\begin{abstract}
This research was designed to examine how early-childhood educators pursuing their graduate degrees perceive the concept of happiness, as conveyed in visual representations. The research methodology combines qualitative and quantitative paradigms using the metaphoric collage, a tool used to analyze visual and verbal aspects. The research population included 32 students from various locations in Israel. The findings revealed that the concept of happiness is perceived as love, spirituality and emotions. In their collages, approximately half of the participants represent happiness as a list of separate and fragmented components such as children, health etc., while others attempted to find connections and relations in order to achieve a more profound view of happiness. Although the majority of the participants experience happiness as something intangible, they did not perceive academic studies and learning processes as a component of happiness.
\end{abstract}

Keywords: happiness, teacher education, visual representation, academic studies

1. The Issue

This research examines how early childhood educators in Israel (i.e. teachers, instructors, supervisors and principals in graduate programs) perceive the concept of happiness, by examining the way they express such perceptions in their visual representations.

Perceptions of happiness and the definition of happiness are among the topics most discussed in the media as well as in popular psychology and self-help literature. In recent years the perception of happiness has gained exceeding awareness by various researchers in the social sciences. Researchers have begun to systematically examining the various components of happiness related to emotions and to connect such components to success and life achievements.

Bilsky (2012) stated that happiness is perceived as satisfaction with life as a whole; happiness cannot be taught and there is no such thing as instant happiness. Happiness may appear or disappear as quickly as one's ability to adapt to change. Bilsky also said that happiness is the ability to love and show empathy toward others and that the key to happiness lies in the development of life skills.

This research was designed to seek answers to four questions: How do the research participants define happiness? Do the research participants have a clear and distinct perception of happiness or do they see happiness as various events or moments throughout life? Do education and learning and the satisfaction as a result thereof play a role in the participant's happiness?

\section{Literature Review}

What is happiness? Although philosophers, poets, writers, and researchers have addressed this question, there is no unequivocal answer. Happiness is composed of numerous components, among them hope, optimism, seeing the half full glass, pleasure, satisfaction, belief in one's strength, all of which amount to thinking positively about life. Fredrickson (2006) claimed that positive emotions play a role in evolution in that they expand our given intellectual, physical, and social resources and build up reserves that can be used when we face threats or opportunities.

Positive psychology is a worldview that leads to happiness (Ben-Shahar 2008), based on the understanding that cognition and emotions are interconnected and inseparable. In the context of positive psychology, Diener and Biswas-Diener (2008) refer to happiness as an important component of psychological well-being and, beyond one's economic condition, a true resource for emotional intelligence and social capital. Accordingly, the components of 
psychological well-being include satisfaction and happiness, spirituality and meaning in life, positive approaches and positive emotions, loving social relations, investment in work and other activities, values and goals to be accomplished, physical and mental health and the material means to meet our needs. Daniel Kahneman's theory of objective happiness (2005) refers to happiness as a subjective feeling at each and every moment. Seligman (2005) defines happiness as a sense of pleasure, satisfaction or emotional well-being accompanied by the feeling that life is good, meaningful and worth living.

The research literature views happiness as constructed of three components: (1) the pleasant life - the feeling that life is good is accompanied by optimism, satisfaction, and joy; (2) the engaged life - the feeling that life is interesting, and hence satisfying and fulfilling; and (3) the meaningful life - the feeling that life is meaningful and worth living. These components have become the empirical basis for studying such areas as positive emotions (Fredrickson 2008), flow which involves total immersion in an activity (Csikszentmihalyi 1997), strengths (Buckingham and Clifton 2010), and hope (Lopez et al. 2004).

Sheldon and Lyubomirsky (2009) showed that in order to be happy, people have work, and that achieving happiness requires learning, practice, and perseverance - much as any other achievement. Pursuing happiness is more of a cognitive and behavioral exercise than an emotional experience and achieving it requires a commitment and responsibility (Prager 2008). Prager also claimed that the commitment to be happy should extend beyond oneself, and include one's spouse and family, as people who are not happy affect their surroundings and cause those close to them to feel bad as well. In contrast, positive emotions and a good disposition make the individual open to others, to the world, to the self, and happy people usually behave better toward others than those who are not happy. Blanchflower and Oswald (2008), whose study included half a million people, claimed that throughout a person's lifetime happiness assumes the shape of a bell curve: it is high at the beginning of life, declines in the middle, and then rises again.

What, then, makes us happy? Sheldon and Lyubomirsky (2009) found a relation between happiness and education. They also found that religious people tend to be happier, as do married people, with married women being happier than their unmarried counterparts. Lyubomirsky, King and Diener (2005) found a bi-directional relation between success in many areas of life and happiness, with success causing people to be happier, and happy people being more successful. These researchers proposed a conceptual model, according to which happiness and success are related not only because success causes happiness but also because positive feelings have an impact on success. Through a meta-analysis of many research studies, they showed that happiness is related to success and even promotes success, while leading to behaviors that accompany success. Moreover, they provided evidence that positive emotions are likely to be the cause of desired characteristics, resources and success related to happiness.

Seligman (2005) defined two major components of happiness - enjoyment and fulfillment. Enjoyment is a rudimentary physical and emotional phenomenon which involves very little action and thought. It fades quickly, and to be maintained, the stimulus must be repeated. Fulfillment involves thought and interpretation, and tends to survive over time, is independent of enjoyment (e.g., intellectual fulfillment). According to Seligman, many people are born without a strong capacity to feel pleasure, and if they delve into the reasons, they will end up with low self-esteem rather than with increased pleasure.

Researchers have found a correlation between happiness and various occupations (Diener and Biswas-Diener 2002; Fisher 2010; Losada and Heaphy 2004; Pryce-Jones 2010). Fredrickson (2008) found that teachers can achieve flexible thinking by fostering positive emotions. Liesveld, Miller, and Robison (2005), who examined the attributes of successful teachers, found that they have the ability to improvise their lesson plans. Bogler (2005) defined fulfillment a component of happiness - as a pleasant and positive emotional condition deriving from appreciating one's work and experiences. The results of her research on work fulfillment among Jewish and Arab teachers reinforce the importance of inner motivational attributes.

In a study of stress among student teachers, Segal and Ezer (2009) revealed that a high level of stress correlated with a low level of emotional well-being in teacher education; conversely, a low level of stress was found to correlate with a high level of well-being among students of education. Segal, Gilat, and Carmeli (2011), who examined perceptions of happiness among education students, found that negative emotions are inversely related to the magnitude of well-being in the teaching profession. Furthermore, this inverse relationship is stronger than the positive relationship. In the present study, the factors found to have the greatest impact on teachers' professional satisfaction are internal. Thus, students' high achievements lead to teachers' high esteem of their work.

The current study is based on the assumption that an understanding of how educators in the field of early childhood perceive the concept of happiness is of major importance, and that educators who are happy can be of greater benefit to their students. 


\section{Method}

The methodological approach chosen for this research incorporates the qualitative paradigm 'Multiple Case Study' (Baxter \& Jack, 2008; Yin, 2003), which enables the exposure of the implicit level of understanding of the participants' perceptions of happiness. In addition, the research uses the theoretical quantitative paradigm in order to examine the frequency of the occurrence of the identified components occurred.

The research took place in Israel and examined 32 female students learning in a graduate program in early childhood education. All of the participants graduated from academic institutions, between the ages of 27-57, having a GPA of 85-95, with a teaching experience ranging between 3-20 years. The participants were preschool teachers, managers of kindergarten clusters and instructors in various disciplines.

The main research tool used for data gathering was the 'Metaphoric Collage' (Zimet-Russo, Avivi-Dan, and Gilat 2009). This research tool is comprised of three steps as follows: (a) expression using visual means (e.g. photos, drawings, writing etc.) at the same time; (b) written analysis of the visual means by the participant; and (c) dialogue between the participant and the researcher with respect to the visual means chosen by the participant and the written analysis (mainly using interviews, questionnaires and narrative discourse). The Metaphorical Collage enabled the researcher to expand its understanding of the research topic. Moreover, the analysis of the participants' written analysis facilitates a broader understanding of the views of the participants.

The data collection process included three stages: (1) creation of a collage (the visual means) expressing the participants' perception of happiness, (2) written verbal explanations by each participant of its collage, (3) a dialogue between the researcher and each of the participants about the collage and the written explanation.

Thereafter the researcher analyzed all of the above findings and conducted three types of analysis to the collected data as follows:

1) Visual Analysis: analysis of the images in the collage by examining constant variables such as area of origin, number of images, connections between the images, location of the images in space, etc.

2) Categorical-Content Analysis: analysis based on the 'Field-Grounded Theory' (Gibton 2001). This theory includes five stages. In the first stage, the 'open coding stage', the researcher sorts and categorizes the data viewed in the collages, and each category received a preliminary name. In the second stage, the exhale coding stage', the researcher groups and organizes related categories. In the third stage, the 'selective coding stage', the researcher compared and combined related categories. In the fourth stage, 'the focal stage', the researcher determines the main categories for analysis and creates hierarchy between the various categories beginning with the highest major category. In the fifth and final stage, the researcher creates either a model or theory.

3) Descriptive Statistical Analysis: analysis to examine the frequency of each category.

\section{Findings}

\subsection{Definitions of Happiness}

\section{Direct and indirect definitions of Happiness}

In analyzing the findings we found two primary approaches to define 'Happiness'. One was the choice to define happiness directly through images describing feelings and sensations of happiness. The other was the choice of indirect definitions through events the participant found related to happiness. In both approaches, the participants completed the following sentence: "Happiness is like..."

Direct definitions of Happiness, showed that "Happiness is: "Like a magic wand that sometimes leads us astray. Its enchanting and we always seek to satisfy it, something coveted and desired" (Limor). "Magic dust scattered from above" (Limor). "Variegated, colorful, it has a variety of colors, shapes, it is not absolute, not straight, it has curves, twists like a string" (Sigal). "A type of emotion that elevates and completes a person, and such that I wish upon myself" (Sigal). "Being separated from reality" (Dikla). "To manage to walk between the drops and at the same time collect them" (Riki). "Everything is open: a wonderful feeling that everything is permitted, that there are no boundaries, that everything is possible (even if this floating is followed by a landing, it was worthwhile...)" (Gitit). "A time of achievement and creativity, because in creativity ... the freedom of creation" (Keren). "Humor, joy, something liberating and also breaking limits and the creativity to produce on my own" (Einat).

All of the collected direct definitions are positive and optimistic. The participants perceive happiness as magical, variegated, colorful, flowing etc. Happiness is an uplifting emotion, showing the inner self and is expressed through creativity and humor.

Indirect definitions of Happiness included negative statements that described situations of unhappiness, as well as 
personal stories bringing the participant close to feelings perceived as happiness. Here are some examples: "During the period when I stopped participating in sports, I understood the meaning of 'lack of happiness,' of sadness, of inner pain" (Inbal). "When I achieve a sense of satisfaction and contentment in my personal emotional and family life, I will come to work with a greater sense of fulfillment and satisfaction and I will be able to give the children more, teach them more and be with them more. I'll be happy" (Merav).

Defining of Happiness as fragmented or unified

The findings revealed that $70.9 \%$ of the participants defined happiness by means of separate and fragmented components, which, in some cases, they attempted to rank or order. The remaining $29.1 \%$ presented their perception of happiness as a unified view that included related and linked components.

Following are four examples that illustrate this continuum of perceptions, ranging from fragmented components to unified components.

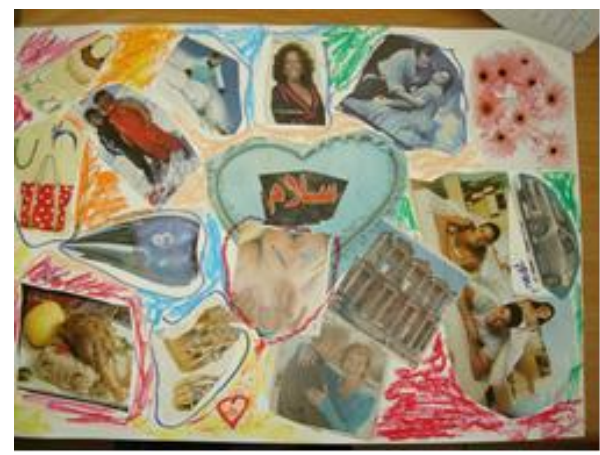

Figure 1. Samia's collage

Samia's collage represents happiness as a list of separate components. She selected 11 items indicative of happiness: "The heart-because to me love is happiness; close family — because family provides happiness; my grandson-because he makes me happy when I'm with him; flowers - because flowers represent the beauty of nature and provide me with serenity and tranquility; children - healthy children make me happy; perfume and shopping-are representative of happiness; $a$ hug - makes me feel good and calm and makes me happy; food-preparing food for my beloved family, makes me feel happy and fulfilled and I feel I'm doing something for my family because they are always away from home; Laughter-laughter shows that I'm happy; skiing-enjoyable trips; and finally, peace-peace is the most important."

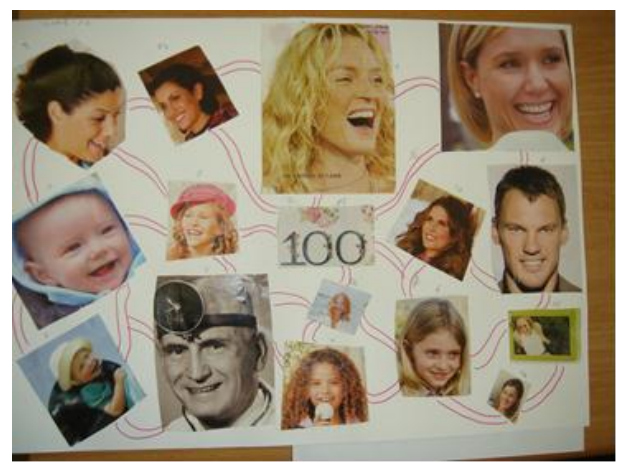

Figure 2. Ettie's collage

In Ettie's collage, her worldview with respect to happiness is conveyed by the number 100, placed at the center, and by the lines connecting all the images to the number 100. She states: "Anyone can lead someone else to happiness, regardless of age, color, occupation, or status." 


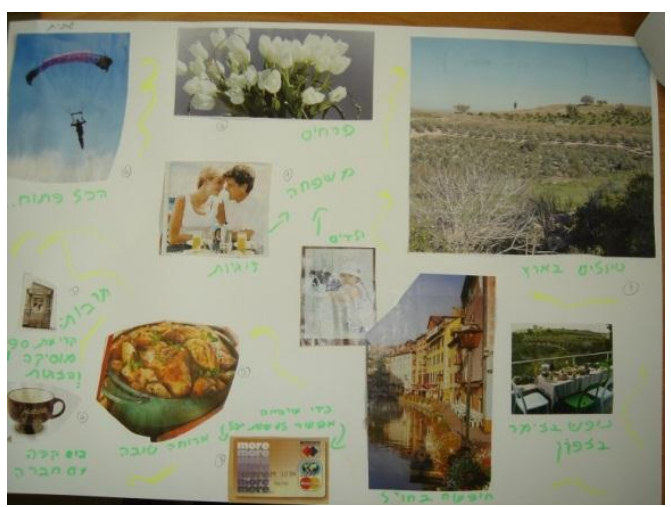

Figure 3. Gitit's collage

Gitit's collage includes an attempt to classify the components in hierarchical order. "I classified them according to priority: family, a cup of coffee with a friend, culture, trips, a good meal, everything is open and feels like all is possible and there are no limitations, flowers and a credit card and a healthy bank account are necessary conditions for achieving all the good things I mentioned."

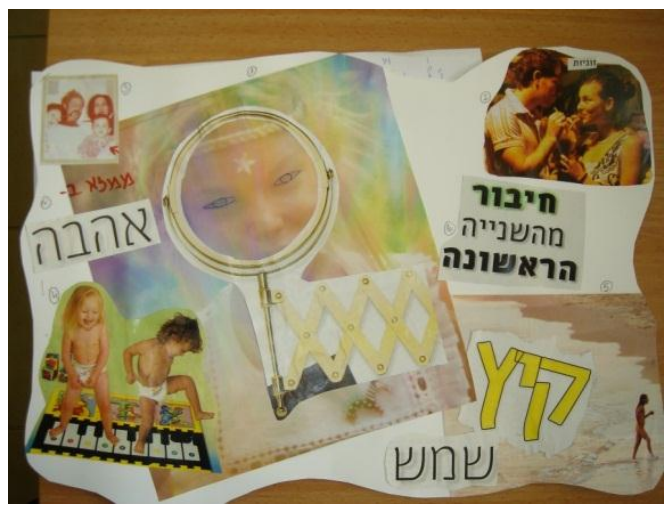

Figure 4. Yaarit's collage

In Yaarit's collage, a unified perception of happiness is represented by means of the connection between the isolated components achieved through the shared background she chose to create. She states: "I decided to cut out the background and not leave it symmetrical because it (happiness) is one of the most unmeasurable feelings. It is something amorphous, with diverse strengths and doses."

\section{Symbols and Images Used to Define Happiness}

The participants referred to a variety of source topics: (i) food - different types, cooked dishes, delicacies, candies etc.; (ii) jewelry - watches, rings etc.; (iii) cosmetics - perfume and lipstick; (iv) nature and landscapes - flowers and sunshine, the sea, different sites, etc.; (v) colors; and (vi) numbers.

Two source topics, people and hearts, were prominent, with people appearing in all the collages. The participants used pictures of children, adults, old people, men, and women. Sometimes they used just parts of the human body, other time parts of the face, hands, eyes, and mouths. There were also references to different bodily expressions reflecting the emotions, such as smiles and touching. This finding points to the participants' understanding of happiness as attributed to human beings, as well as their deep identification with the concept. For example see collages in Figure 5.

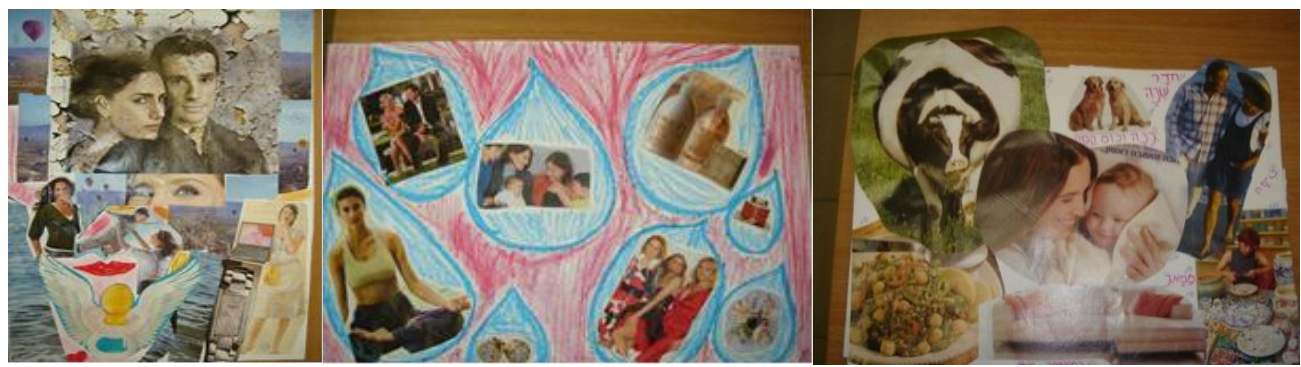

Figure 5. Representations of humans and of the human body 
The heart as a symbol of happiness appeared in $42 \%$ of the collages (13 out of 31 collages analyzed), all colored blue or red and of various sizes. Some of the collages included one heart and others had more, and in some cases the heart appeared with another representation. We demonstrate this finding with a number of examples, where the heart image expresses happiness differently in each (See Figure 6).

The frequent and conspicuous use of the heart can point to the participants' implicit understanding of how happiness is related to love, to spirituality, and to the emotions. The participants do not state this explicitly, but the choice of the heart as a symbol in so many of the collages leads to this perception of happiness.

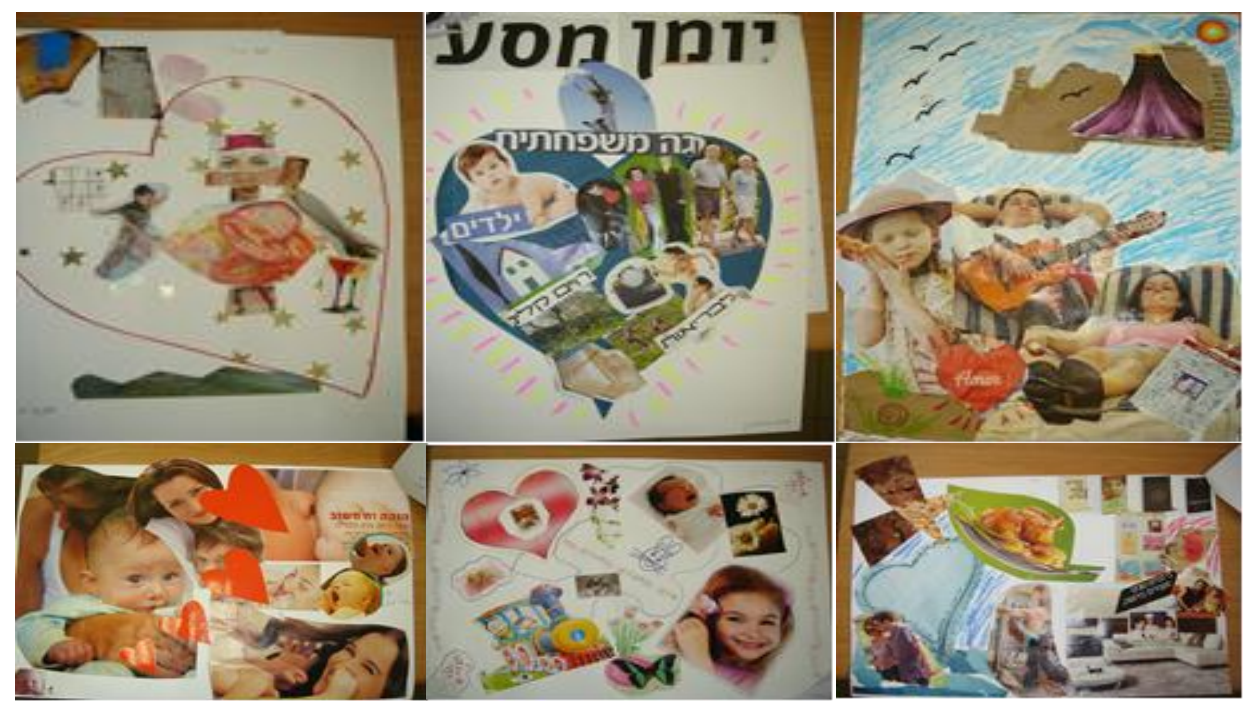

Figure 6. Heart representations

\subsection{Categorical Analysis with Statistical Validation}

This part of the analysis analyzed the participants' verbal explanations of the images they chose. We recognized seven categories representing the participant's perception of Happiness. We will presents for each category an example from the students' discourse and indicate its frequency among all the participants.

The first category refers to how the participants chose to define Happiness.

\section{The First Category: Personal statements vs. generally used patterns}

Personal statements are sentences in which participants write what personally makes them happy. For example: "Happiness is my immediate family, it's my children ..." (Limor). "In my life dancing is whatmakes me happy. When I dance, the whole world is mine, and I feel supremely happy" (Dikla).

General and routine statements are patterns generally used to describe happiness without contemplating or processing the participants' personal thoughts and experiences. Such statements are part of written or spoken general knowledge that people generally use in open discourse. For example: "Happiness is like the air we breathe" (Noga). "Happiness is the taste of life" (Dorit). "Happiness is found in the small moments of our lives" (Anat).

Our examination of the frequency of descriptions of happiness in personal statements compared to those in generally used patterns showed that $35.48 \%$ used personal statements and $32.26 \%$ used routine statements.

\section{The Second Category: Thoughts, sensations, and emotions of happiness}

The second category emphasizes the differences found in the participants' statements with respect to the essence of happiness. What is happiness? a thought, a sensation, or perhaps a feeling?

The following examples from the participants' statements demonstrate their perception of happiness as intellectual taught, sensations, or emption.

Happiness as a taught: "Happiness is a process of change in perception. . Unless we change how we think and perceive of reality, happiness will not be accessible to us" (Idit).

Happiness as a sensation: "For me happiness is a feeling of warmth" (Name). "Happiness is a set of fragrances, aromas and tastes accompanying us every day" (Limor).

Happiness as an emotion: "[Happiness is] a genuine moment when I feel that my spouse and I are truly together, usually 
accompanied by a sense of truth, protection, and love throughout the body" (Yaarit). "Happiness gives me a sense of security. When I'm happy I feel safe" (Limor).

In examining the frequency of references to happiness as taught, sensations, or emotions, we found that $37 \%$ of the participants described happiness in terms of taught and another 37\% used all three: taught, sensations and emotions, in parallel to describe happiness.

\section{The Third Category: Happiness as an ongoing experience vs. happiness as a momentary event}

The third category refers to the perception of happiness as an ongoing experience vs. the perception of happiness as a specific and one-time event?

Happiness as an ongoing experience: "Happiness plays like a tune, it is slowly connected into a wonderful melody" (Limor). "The road to happiness is a journey beginning on the day you are born and continues throughout life the journey brings additional happiness" (Merav).

Happiness as a momentary event: "I encountered the number 100, which for me represents the summit to be reached. And I decided that all of the figures reach 100 on their summit of happiness" (Ettie).

In examining the frequency of references to happiness as an ongoing experience compared to a momentary event, we found that $48.39 \%$ of the participants described happiness as a momentary event and $25.8 \%$ as both a momentary event and an ongoing experience, and only $19.35 \%$ see happiness as an ongoing experience.

\section{The Fourth Category: The connection between time and happiness}

The fourth category is an extension of the third category and refers to happiness in the context of the past-present-future timeline. Do the participants see happiness as an experience that occurred in the past, and do they remember specific experiences that left an impression upon them? Or is happiness perhaps something that happens here and now?

The following examples show references to happiness with respect to time.

Past: "Tastes from the past and the present" (Limor). "For me the cow in the meadow symbolizes great happiness because it reminds me of our trip to Holland five years ago" (Keren).

Present: "The here and now... happiness is momentary and not dependent upon place or time" (Ettie).

Future: "Not yet obtained" (Idit). "Happiness is infinite" (Inbal). "When you grow old with your beloved spouse" (Merav).

An examination of the frequency of references to happiness as something remembered (past), something in the present or something not yet known (future) revealed that $43 \%$ of the participants refer to happiness in the present tense, $11 \%$ as something timeless, $14 \%$ as something in the past, $14 \%$ in the past and the present, and $18 \%$ as something in all times.

\section{The Fifth Category: Happiness as a tangible experience or intangible experience}

The fifth category distinguishes between participants' perceptions of happiness as tangible experience (good food, money, objects) vs intangible experience (knowledge, serein).

Happiness as a tangible experience: "King David Hotel, spa, material pleasures, trips, delicious meals" (Ariella). "Food makes me feel happy when I'm sad, anxious" (Hagar). "A picture of gold and diamonds, work, money, wealth" (Riki). "A credit card and a healthy bank account " (Gitit).

Happiness as an intangible experiences. "Intellectual stimulation, freedom and quiet" (Iris).

The comparison between happiness as a tangible experience vs happiness as an intangible experience revealed that $64.52 \%$ of the participants considered happiness to be an intangible experience, $12.90 \%$ as a tangible experience and $19.35 \%$ as both tangible and intangible.

The Sixth Category: Is everything predetermined or do we have the right to choose

The sixth category examined how happiness is related to the individual's choice.

The following examples demonstrate the participants' perceptions of the individual's choice and responsibility in attaining happiness: "The ability to see and observe and to notice everything that happens around me, and particularly things that cause me happiness, because many times we experience happiness in retrospect and forget to concentrate on the actual moment when we had the feeling" (Yaarit). "It's a good idea to make it a habit, at least once a week, to find time for myself to do things I love" (Dorit). "I choose to hold on to what I have in order to stay happy and not be bitter and insufferable" (Hannah).

In contrast, some of the participants saw a connection between happiness and fate. For them happiness is not a choice and depends upon other factors over which they have no control: "A happy person cannot stand alone. Someone or 
something else caused the happiness" (Ettie).

An examination of the frequency of statements about happiness as something predetermined or as a matter of choice showed that $45.16 \%$ of the students saw external factors as determining happiness, while $32.26 \%$ choose to take responsibility for happiness and $12.90 \%$ indicated that both they themselves and other factors were responsible for their happiness.

\section{The Seventh Category: Giving to or receiving from others as factors in happiness}

The following examples demonstrate giving as a factor in happiness. "Food... preparing it for others...preparing it with others" (Ariella). "Being together, helping and being helped, connecting and being connected, influencing and being influenced" (Yaarit).

The following statement demonstrates receiving from others as a cause of happiness. "I receive and want more" (Virginia).

We compared the frequency of statements indicating that giving is the cause of happiness and those that referred to receiving as the cause. We found that $3.23 \%$ of the participants referred to happiness as giving, $19.35 \%$ referred to it as receiving and $25.81 \%$ saw happiness both as giving and as receiving.

\subsection{Analysis with Statistical Validation of the Participants' Unique Attributes}

The participants are female students learning in a graduate program in early childhood education. All of the participants graduated from academic institutions, with a teaching experience ranging between 3-20 years all as set forth above.

The participants group included preschool teachers, managers of kindergarten clusters and instructors in various disciplines.

In this research we attempt to examine whether academic study is perceived as related to happiness.

Of the 32 participants, only one student indicated that her studies cause her happiness. "the satisfaction from my work and my achievements makes me happy" (Dorit).

We found that only $6.45 \%$ of the participants mentioned work and studies as a source of happiness, while $93.55 \%$ did not mention work or studies as a component of happiness.

In summary, the research findings point to variance among the participants with respect to how they perceive happiness. We found that in general, happiness is attributed to relationships with other people, and the heart represents the perception of happiness as being both a pattern and a personal experience. Some perceive happiness as a list of separate and fragmented components, while others attempted to find connections and relations directed at a more profound view of happiness, and also as thoughts, sensations, and emotions. Almost half the participants experience happiness as something intangible. Most perceive happiness as something momentary and not as an ongoing experience, and they see happiness as dependent upon factors other than the individual. In addition, most participants speak about happiness in terms of the here and now.

Moreover, the research found that in all categories, the participants did not make a connection between their academic studies and their happiness.

\section{Discussion}

This study was designed to examine the perception of the concept of happiness, using metaphoric collages as a medium. The participants were educators studying for master's degrees in early childhood education.

The entire research population consisted of women, and consequently the findings are gender biased. According to Gilligan (1982), male and female identities are fixed and are not the product of sociocultural structuring. According to her, the female essence differs from the male essence, with the difference deriving from a different view of "self" and expressed in how women and men relate to the environment. Each gender represents a different social model and mode of behavior.

Happiness has numerous components, among them hope, optimism, pleasure, fulfillment, belief in strengths and others (Ben-Shahar 2008).

The participants' statements did not refer to their strengths and abilities as components of happiness. On the contrary, some chose to define happiness as the opposite of reality and elusive, and demonstrated this using examples from their past experiences. Kahneman et al. (2005) explain this by arguing that we usually judge our past experiences according to how we felt at the peak of the experience (good or bad). We remember how pleasant the experience was and are also affected by the duration of the experience, and we do not relate to an overall view of life in the context of our sense of happiness. 
The research findings indicate that only a few participants see happiness as a tangible experience related to pleasure. Two-thirds view it as an intangible experience involving fulfillment, and one-fifth perceive happiness as both tangible and intangible experience. In other words, only a minority derives pleasure from tangible experiences.

Another finding refers to giving and contributing to one's family as factors that reinforce and encourage feelings of happiness. This finding is supported in the research literature (Frederickson 2008), which stresses the importance of the engaged life for achieving a sense of pleasure, fulfillment and a meaningful life.

Seligman (2005) showed that the positive effect of happiness that remains after enjoyable activity pales in comparison to the effect of giving from the generosity of one's heart. In the current research only a minority of the participants referred to giving as a factor causing happiness.

The study also found that there are not many differences between research participants who used personal statements and those that used patterned statements. This finding seems to point to the erosion in the discussion of the concept of happiness, the desire to achieve it and the search for it. Gilbert (2006) explained how cultures fall into the trap of deceptive beliefs and hold onto unrealistic beliefs about happiness, for example, that pleasure is derived from money, and that pleasure is derived from children. Walker (1977), who measured the level of satisfaction among people with children, found that their satisfaction dropped dramatically after the birth of their first child and rose again only after the children had left home. A statement like "children are happiness" is a huge duplicity, a social convention, and a false belief that was also found among the participants in this study. Kahneman et al. (2005) examined the emotions of women as they carried out their everyday activities and showed that they are less happy when taking care of children than when engaged in other routine activities. It is noteworthy that about half of the participants managed to free themselves of deceptive beliefs, look inside themselves, and relate to happiness from a purely personal perspective.

Another finding refers to the frequency of statements about happiness as something remembered, currently present, or not yet known Gilbert (2006) pointed to the important role of thoughts about the future in causing pleasure. Imaginative pictures of the future are of major importance, not necessarily because we want or expect these things to happen but rather because raising these possibilities in the imagination is a source of pleasure. Singer (1981) indicated that when people daydream about the future they tend to see themselves as effective and successful and not as having difficulties or failing, and for this reason thoughts of the future are likely to cause great pleasure.

Although all the participants are graduate students engaged in teaching, and although the research itself was carried out at a college, only one student pointed to her studies as a source of happiness, and only one student pointed to her work as a source of happiness: "Fulfillment at work and my accomplishments." The rest did not mention studies or work as factors contributing to their happiness.

Gradient students are primarily trained to develop rational thinking, and their curriculum includes academic courses on leadership, management, and developmental child psychology. The program does not include courses focusing on life skills, spirituality, emotions or on positive psychology and empowerment, which have been found to influence perceptions of happiness.

Ariely (2010) points to the strong affinity between identity and work, viewing work as an inseparable part of one's identity and not merely a way to earn money. "The ability to translate pleasure into willingness to work is to a large extent dependent upon the meaning we attribute to our work" (p. 84). Hence, in order to enhance students' happiness, perhaps colleges should raise awareness of the importance of fulfillment and of hard work in challenging and boosting individual happiness.

\section{The Metaphoric Collage as a Research Tool}

The metaphoric collage is a research tool that enables participants to reveal their worldviews visually and verbally, and offers the simultaneous use of two types of languages - the choice of a visual image and the verbal explanation - as a means of understanding thought. "The collage enabled me to work on a number of levels and present them" (Chen). "The visual stimuli reveal the positive components of happiness. Can I produce or increase my own happiness?" (Keren).

One of the advantages of the metaphoric collage that it supports participants' memory and helps them connect to their perception of the topic under study. By browsing through the images, the participants 'browse through their own consciousness'. "The collage made me look inside myself, gave me the confidence to express my thoughts, to know that everything I do is good and right for me" (Yaarit).

In preparing their collages, the participants experienced inner processes through their interaction with the materials. At the same time they focused on the research question: what is happiness for me? This dual process enabled them to arrive at places that perhaps would have been forgotten if the question had been asked verbally and the images represented by pictures and words help to translate and enrich their understanding. "The collage made me look inside myself. The 
collage gave me the confidence to express my thoughts, to know that everything I do is good and right for me. The collage motivated my thoughts, and flooded me with pleasant memories. The collage helped me connect things from the past and the present and even to think about the process that connects them" (Keren).

Finally, the researcher's request to explain the chosen images forces the participants to reflect deeply. It should be noted that participants do not always give the same explanation of their visual images at the beginning and the end of the process. Participants may choose an image intuitively or rationally but do not always stop to think why. By asking the participants to explain the chosen images intelligently and in writing, the researcher obliges participants to stop and think and to justify their choices. These ideas are supported by Arnheim (1966), who stated that the material used in art has an impact on directing and guiding the artist, and by Goodman (1976), who claimed that art a language of its own that can be used to generate a dialogue with the observer.

\section{Conclusion}

This study is the first to examine students' perceptions of the concept of happiness using the metaphoric collage tool, and reveals interesting directions in the general perception of happiness and in the academic studies as a component of happiness. The results of this study reinforce the understanding that students differ in their perceptions of happiness. We believe that discourse on this topic should be encouraged at teacher-education colleges in order to raise students' awareness of their own happiness, of the components influencing their happiness, and of the role and contribution of empowering their sense of happiness. Expanding knowledge about how students conceptualize and experience happiness could improve teacher education programs. These programs can become more effective when integrated with components that increase happiness in order to help improve student well-being and, as studies on this topic indicate, even have an impact on their degree of motivation and satisfaction, both as students and as practicing educators. We recommend further research to extend the research population to additional groups, among them male students, those enrolled in other teacher education programs, and existing and future teaching teams.

\section{References}

Arnheim, R. (1966). Toward a psychology of art. Berkeley: University of California Press.

Ariely, Dan (2010). The upside of irrationality. New York: HarperCollins.

Baxter, P., \& Jack, S. (2008). Qualitative case study methodology: Study design and implementation for novice researchers. The Qualitative Report, 13, 544-559.

Ben Shahar, T. (2008). In happiness. Tel Aviv: Matar (Hebrew).

Bilsky, R. (2012). The magic of happiness. Jerusalem: Magnes Press, Carmel Publishing (Hebrew).

Blanchflower, D. J., \& Oswald, A. J. (2008). Is well-being U-shaped over the life cycle? Social Science \& Medicine, 66 (8), 1733-1749. http://dx.doi.org/10.1016/j.socscimed.2008.01.030

Bogler, R. (2005). Empowering teachers as a mediating factor in the relation between including teachers in decision-making and their obligations to the profession. In A. Paldi (Ed.), Education in the test of time (pp. 156-173). Tel Aviv: Histadrut Hamorim and Reches Educational Projects(Hebrew).

Buckingham, M., \& Clifton, D. (2010). Now, discover your strengths. New York: Free Press.

Csikszentmihalyi, M. (1997). Finding flow: The psychology of engagement with everyday life. New York: Basic Books.

Diener E., \& Biswas-Diener R. (2002). Will money increase subjective well-being? A literature review and guide to needed research. Social Indicators Research, 57, 119-169. http://dx.doi.org/10.1023/A:1014411319119

Diener, E. \& Biswas-Diener, R. (2008). Happiness: Unlocking the mysteries of psychological wealth. Hoboken, NJ: Blackwell Publishing. http://dx.doi.org/10.1002/9781444305159

Fisher, C. (2010). Happiness at work. International Journal of Management Reviews, 12, (4), 384-412. http://dx.doi.org/10.1111/j.1468-2370.2009.00270.x

Fredrickson, B. L. (2006). Unpacking positive emotions: Investigating the seeds of human flourishing. Journal of Positive Psychology, 1, 57-60. http://dx.doi.org/10.1080/17439760500510981

Fredrickson, B. L. (2008). Promoting Positive Affect. In M. Eid \& R. J. Larsen (Eds). The science of subjective well-being (pp. 449-468), New York: Guilford Press.

Gibton, D. (2001). Grounded theory: The meaning of data analysis and building a theory of qualitative research. In N. Zabar Ben-Yehoshua (Ed.), Traditions and streams in qualitative research (pp. 195-227). Tel Aviv: Dvir(Hebrew).

Gilbert, D. (2006). Stumbling on happiness. New York: Knopf. 
Gilligan, C. (1982). In a different voice: Psychological theory and women's development. Cambridge, MA: Harvard University Press.

Goodman, N. (1976). Languages of art. Indianapolis, IN: Hackett.

Kahneman, D. et al. (2005). Rationality, fairness, happiness: Selected articles. M. Bar Hillel (Ed.). Haifa: University of Haifa, and Jerusalem: Keter Publishing (Hebrew).

Liesveld, R., Miller, J. A., \& Robison, J. (2005). Teach with your strengths: How great teachers inspire their students. New York: Gallup Press.

Lopez, S. J., Snyder, C. R., Magyar-Moe, J., Edwards, L. M., Pedrotti, J. T., Janowski, K., Turner, J. L., \& Pressgrove, C. (2004). Strategies for accentuating Hope. In P. A. Linley, \& S. Joseph (Eds.) Positive psychology in practice (pp. 388-404). Hoboken, NJ: Wiley.

Losada, M. \& Heaphy, E. (2004). The role of positivity and connectivity in the performance of business teams: A nonlinear dynamics model. American Behavioral Scientist, 47, 40-765. http://dx.doi.org/10.1177/0002764203260208

Lyubomirsky, S., King, L., \& Diener, E. (2005). The benefits of frequent positive affect: Does happiness lead to success? Psychological Bulletin, 131, 803-855. http://dx.doi.org/10.1037/0033-2909.131.6.803

Prager, D. (2008). Happiness is a serious business. A human natural repair book. New York: Harper.

Pryce-Jones, J. (2010). Happiness at work: Maximizing your psychological capital for success. Hoboken, NJ: Wiley-Blackwell. http://dx.doi.org/10.1002/9780470666845

Segal, S., Gilat Y., \& Carmeli, G. (2011). The happy teacher educator - Is this necessary and is it possible? Research Report. Tel-Aviv: Levinsky College of Education and Mofet Institute (Hebrew).

Segal, S., Ezer, H., \& Gilat, Y. (2009). Stress in teacher education and its effects on the student teachers. Research report. Tel Aviv: Levinsky College of Education and Mofet Institute.

Seligman, M. (2005). Genuine happiness. Ben Shemen, Israel: Am Oved (Hebrew).

Sheldon, K. M., \& Lyubomirsky, S. (2009).Change your actions, not your circumstances: An experimental test of the Sustainable Happiness model. In A. K. Dutt \& B. Radcliff (Eds.), Happiness, economics, and politics: Towards a multi-disciplinary approach. (pp. 324-342). Cheltenham, UK: Edward Elgar. http://dx.doi.org/10.4337/9781849801973.00024

Singer, J. (1981). Daydreaming and fantasy. Oxford: Oxford University Press.

Walker, C. (1977). Some variations in marital satisfaction. In R. Chester \& J. Peel, (Eds.) Equalities and Inequalities in Family Life (pp. 39-127). London: Academic Press.

Yin, R. K. (2003). Case study research: Design and methods (3rd ed.). Thousand Oaks, CA: Sage.

Zimet-Russo, G., Dan-Avivi, Y., \& Gilat, Y. (2009). The metaphoric collage as a tool in the research field. Dapim 48, 163-201 (Hebrew).

\section{(c) $\mathbf{E Y}$}

This work is licensed under a Creative Commons Attribution 3.0 License. 